\title{
Hubungan Faktor Lama Menderita DM dan Tingkat Pengetahuan dengan Distres Diabetes pada Penderita Diabetes Mellitus Tipe 2 Tahun 2017 (Studi di Wilayah Kerja Puskesmas Rowosari, Kota Semarang)
}

\author{
Fitrianur Laili $^{1}$, Ari Udiyono ${ }^{1}$, Lintang Dian Saraswati ${ }^{1}$ \\ ${ }^{1}$ Bagian Epidemiologi Dan Penyakit Tropik, Fakultas Kesehatan Masyarakat, Universitas Diponegoro
}

Info Artikel : Diterima 1 Februari 2019 ; Disetujui 13 Maret 2019 ; Publikasi 29 April 2019

\begin{abstract}
ABSTRAK
Latar Belakang : Distres Diabetes adalah suatu kondisi yang banyak dialami oleh penderita Diabetes Mellitus (DM). Sebagaimana disebutkan sebesar $48,5 \%$ penderita DM Tipe 2 berisiko terkena Distres Diabetes. Tujuan dari penelitian ini adalah untuk mendeskripsikan dan menganalisis hubungan antara durasi DM dan tingkat pengetahuan mengenai Distres Diabetes pada penderita DM Tipe 2 tahun 2017.

Metode : Populasi dalam penelitian ini adalah penderita DM Tipe 2 yang tercatat di Puskesmas Rowosari, Kota Semarang, tahun 2017, yang berjumlah 231 orang. Sampel minimal adalah 100 responden yang diambil dengan metode sampel acak sederhana, dan analisis data menggunakan uji Rank-Spearman dengan interval kepercayaan $95 \%$.

Hasil : Hasil menunjukkan bahwa rerata durasi DM adalah 4,66 tahun, rerata tingkat pengetahuan adalah 4,33 poin, dan rerata skor distres diabetes adalah 51,16 poin. Nilai signifikansi untuk variabel durasi DM dan tingkat pengetahuan masing-masing adalah $\mathrm{p}=0,005(\mathrm{r} p=-0,280)$ dan $\mathrm{p}=0,001(\mathrm{r} p=-0,654)$.

Simpulan : Simpulan dari penelitian ini adalah terdapat hubungan antara durasi DM dan tingkat pengetahuan dengan distres diabetes.
\end{abstract}

Kata Kunci : Distres Diabetes, durasi DM, tingkat pengetahuan

\begin{abstract}
Title : The Association between Duration of Diabetes Mellitus and Level of Knowledge with Distress Diabetes in Type 2 Diabetes Mellitus Patients, 2017 (Study in Rowosari Public Health Center, Semarang City)
\end{abstract}

Background : Distress Diabetes was a condition that was common in people with diabetes. As many as $48.5 \%$ of people with type 2 diabetes were at risk of developing diabetic distress. The purpose of this study was to describe and analyze the relationship between duration of DM and level of knowledge with distress diabetes in type 2 DM patients in 2017.

Method: The population were all type 2 Diabetes Mellitus patients recorded at Rowosari Public Health Center, Semarang City in 2017, namely 231 patients. The minimum sample size was 100 respondents with a simple random sampling method. And for data analysis used sperman rank test with $95 \%$ significance level.

Result : The results showed that the average duration of DM was 4.66 years, the average level of knowledge was 4.33 points, and the average score of diabetic distress was 51.16 points. As for the significance value for the duration of DM variable $(p=0.005 ; r p=-0.280)$ and level of knowledge variable $(p=0.001 ; r p=-0,654)$. Conclusion : So the conclusion of this study that there was a significant relationship between the duration of DM variable and level of knowledge variable with diabetes distress.

Keywords : Diabetes Distress, Duration of DM, Level of Knowledge

\section{PENDAHULUAN}

Distres diabetes adalah suatu kondisi distres yang dapat dialami oleh penderita Diabetes, yang mana mengacu kepada ketakutan akan komplikasi penyakit, kekhawatiran tentang hipoglikemia, dan berbagai tekanan, ketegangan, serta kekhawatiran orang sekitar, yang mana hal ini dialami dapat dialami setiap hari oleh penderita DM. Selain itu, distres ini dapat muncul karena penderita Diabetes mengalami perubahan pola hidup yang secara mendadak, seperti pengaturan pola makan, aktivitas fisik, dan pengkonsumsi obat antidiabetik yang harus dilakukan secara rutin.,

Berdasarkan penelitian di San Francisco disebutkan bahwa dalam 18 bulan sebanyak sepertiga sampai setengah dari penderita diabetes 
akan mengalami distres diabetes. ${ }^{3}$ Hal ini sebanding dengan penelitian yang di Bangladesh, yang mana menunjukkan bahwa $48,5 \%$ penderita DM tipe 2 mengalami distres dengan rincian $26,1 \%$ mengalami distres sedang dan $22,4 \%$ mengalami distres tinggi. ${ }^{4}$

Faktor lama menderita DM dan tingkat pengetahuan termasuk ke dalam faktor yang berperan terhadap terjadinya distress diabetes. Seseorang yang baru terdiagnosis menderita diabetes lebih berisiko untuk mengalami distress. Hal ini diperkuat dengan penelitian di Bangladesh yang menunjukkan adanya hubungan antara lama menderita DM dengan distress diabetes $(p<0,001) .{ }^{4}$ Selain itu, untuk penderita dengan tingkat pengetahuan kurang juga cenderung lebih berisiko untuk mengalami distres diabetes. Hal ini diperkuat dengan penelitian di RSUD Dr. Moewardi, Surakarta yang menunjukkan bahwa tingkat pengetahuan dengan distres diabetes memiliki hubungan yang signifikan $(p<0,001) .^{5}$

Sampai saat ini, masih terdapat hasil penelitian yang secara statistik menunjukkan hasil yang berbeda mengenai faktor-faktor yang berhubungan dengan distres diabetes pada penderita Diabetes Mellitus tipe 2. Oleh karena itu, peneliti tertarik untuk meneliti hubungan faktor lama menderita DM dan tingkat pengetahuan dengan distres diabetes pada penderita Diabetes Mellitus tipe 2.

\section{MATERI DAN METODE}

Jenis penelitian yang digunakan dalam penelitian ini adalah observasional analitik. Dalam penelitian ini, peneliti menggunakan rancangan penelitian cross sectional, sedangkan teknik pengambilan sampel menggunakan metode simple random sampling. Adapun populasi sampel adalah semua penderita Diabetes Mellitus tipe 2 yang terdata di Puskesmas Rowosari, Kota Semarang pada tahun 2017, yaitu sebesar 231 penderita. Sedangkan besar sampel minimal yang diambil sejumlah 100 responden. Dan analisis data yang digunakan adalah uji korelasi rank sperman karena distribusi data tidak normal.

\section{HASIL DAN PEMBAHASAN}

Hasil penelitian untuk hubungan faktor lama menderita DM dan tingkat pengetahuan dengan Distres Diabetes di wilayah kerja Puskesmas Rowosari adalah sebagai berikut :

Tabel 1. Distribusi Frekuensi Lama DM Responden

\begin{tabular}{ll}
\hline Variabel Lama DM & Nilai \\
\hline Mean & 4,66 \\
Median & 4,00 \\
Modus & 2 \\
Minimal & 1 \\
Maksimal & 20 \\
\hline
\end{tabular}

Berdasarkan tabel 1, diketahui bahwa dari 100 responden di wilayah kerja Puskesmas Rowosari, rata-rata lama menderita DM adalah 4,66 tahun.

Tabel 2. Distribusi Frekuensi Tingkat Pengetahuan

\begin{tabular}{ll}
\hline Variabel & Nilai \\
Tingkat Pengetahuan & \\
\hline Mean & 4,33 \\
Median & 4,00 \\
Modus & 0 \\
Minimal & 0 \\
Maksimal & 12 \\
\hline
\end{tabular}

Berdasarkan tabel 2, diketahui bahwa dari 100 responden di wilayah kerja Puskesmas Rowosari, rata-rata skor tingkat pengetahuan yang diperoleh responden adalah 4,33 poin.

Tabel 2. Distribusi Frekuensi Distres Diabetes

\begin{tabular}{l|l}
\hline Variabel & Nilai \\
Distres Diabetes & \\
\hline Mean & 51,16 \\
Median & 53,00 \\
Modus & 53 \\
Minimal & 27 \\
Maksimal & 72 \\
\hline
\end{tabular}

Berdasarkan tabel 3, diketahui bahwa dari 100 responden di wilayah kerja Puskesmas Rowosari, rata-rata skor distres diabetes yang diperoleh responden adalah 51,16 poin.

\section{Hubungan Lama Menderita DM dan Distress Diabetes}

Tabel 4. Tabulasi Silang antara Lama DM dengan Distres Diabetes

\begin{tabular}{ccccc}
\hline Lama DM & \multicolumn{4}{c}{ Distres Diabetes } \\
\cline { 2 - 5 } & \multicolumn{3}{c}{ Ya } & \multicolumn{3}{c}{ Tidak } \\
\cline { 2 - 5 } & $\mathrm{f}$ & $\%$ & $\mathrm{f}$ & $\%$ \\
\hline 0-10 tahun & 50 & 54,9 & 41 & 45,1 \\
$>10$ tahun & 2 & 22,2 & 7 & 77,8 \\
\hline Jumlah & 52 & 52,0 & 48 & 48,0 \\
\hline
\end{tabular}

$* \mathrm{P}_{\text {value }}=0,005 ; \mathrm{r}_{\mathrm{p}}=-0,280$

(uji korelasi rank spearman)

Dilihat dari tabel 4, proporsi responden dengan lama menderita DM 0-10 tahun yang memiliki distres diabetes lebih besar $(54,9 \%)$ dibandingkan proporsi responden dengan lama menderita DM >10 tahun yang memiliki distres diabetes dengan selisih $32,7 \%$. Berdasarkan hasil uji korelasi rank spearman diperoleh nilai $p=$ 0,005, hal ini berarti ada hubungan yang signifikan antara lama menderita DM dengan distres diabetes pada penderita diabetes mellitus tipe 2 di wilayah kerja Puskesmas Rowosari. Adapun hasil nilai $\mathrm{r}$ adalah -0,280 yang berarti kekuatan korelasi lemah dengan arah hubungan korelasi linear negatif, yang artinya semakin lama orang tersebut menderita 
DM, maka akan semakin rendah tingkat distress diabetes pada penderita diabetes mellitus tipe 2 .

Lama menderita DM berperan terhadap terjadinya distres pada penderita DM tipe 2. Orang yang sudah lama menderita DM cenderung memiliki tingkat distress yang ringan. Hal ini karena orang tersebut sudah memiliki cara mekanisme koping atau beradaptasi yang lebih baik dengan keadaan penyakitnya. Pasien yang menderita DM lebih lama akan lebih mampu memahami keadaan yang dirasakannya, baik dari segi fisik, psikologis, hubungan sosial, dan lingkungan. Dan pemahaman ini muncul karena pasien sudah lebih tahu dan berpengalaman terhadap penyakitnya sehingga akan mendorong pasien untuk lebih mampu mengantipasi terjadinya kegawatan atau sesuatu hal yang mungkin akan terjadi pada diri pasien suatu saat nanti. ${ }^{6,7}$

Pada penelitian yang dilakukan di Bangladesh menunjukkan bahwa lama menderita DM dengan distres diabetes memiliki hubungan yang signifikan $(p<0,001)$, Hasil penelitian tersebut menunjukkan proporsi responden yang menderita DM selama 010 tahun yang memiliki risiko distres diabetes 6 kali lebih besar $(70,5 \%)$ dibandingkan proporsi responden yang menderita DM selama $>10$ tahun yang memiliki distres diabetes. ${ }^{4}$ Selain itu, pada penelitian yang juga dilakukan oleh RSI Surakarta menunjukkan bahwa proporsi penderita distress diabetes dengan lama menderita $<5$ tahun lebih besar $(33,0 \%)$ dibandingkan dengan penderita distress diabetes dengan lama menderita $\geq 5$ tahun. Dalam penelitian tersebut juga memiliki nilai $\mathrm{p}=0,001$ dan nilai $\mathrm{r} p=-0,674$ (ada hubungan signifikan dan kekuatan korelasi kuat). ${ }^{7}$ Hal ini mendukung teori bahwa orang yang baru menderita DM masih belum bisa beradaptasi terkait adanya perubahan pola hidup yang mendadak.

Berdasarkan penjelasan dari hasil penelitian terdahulu, maka diketahui bahwa ada kesesuaian antara teori serta kesesuaian terhadap penelitian sebelumnya dengan hasil analisis hubungan antara lama menderita DM dengan distres diabetes, dimana dari hasil analisis hubungan menunjukan adanya hubungan yang signifikan antara lama menderita DM dengan distres diabetes, walaupun kekuatan hubungan yang dimiliki tergolong lemah dan bersifat tidak searah $(\mathrm{p}=0,005 ; \alpha=0,05 ; \mathrm{r}=$ $0,280)$. Hal ini berarti, semakin lama orang tersebut menderita DM, maka akan semakin rendah tingkat distress diabetes pada penderita diabetes mellitus tipe 2. Terbukti dari hasil penelitian bahwa orang yang menderita distress diabetes dan menderita DM $\leq 10$ tahun memiliki proporsi dua kali lebih besar $(32,7 \%)$ dibandingkan orang yang menderita distress diabetes dan menderita DM >10 tahun.

\section{Hubungan Tingkat Pengetahuan dan Distres Diabetes}

Tabel 5. Tabulasi Silang antara Tingkat Pengetahuan dengan Distres Diabetes

\begin{tabular}{lllll}
\hline Tingkat & \multicolumn{3}{c}{ Distres Diabetes } \\
\cline { 2 - 5 } Pengetahu & \multicolumn{3}{c}{ Ya } & \multicolumn{3}{c}{ Tidak } \\
\cline { 2 - 6 } an & $\mathrm{f}$ & $\%$ & $\mathrm{f}$ & $\%$ \\
\hline Kurang & 36 & 78,3 & 10 & 21,7 \\
Baik & 16 & 29,6 & 38 & 70,4 \\
\hline Jumlah & 52 & 52,0 & 48 & 48,0 \\
\hline$* P_{\text {value }}=0,001 ; \mathrm{r}_{\mathrm{p}}=-0,654$ & & &
\end{tabular}

(uji korelasi rank spearman)

Dilihat dari tabel 5, proporsi responden dengan tingkat pengetauan kurang yang memiliki distres diabetes lebih besar $(78,3 \%)$ dibandingkan proporsi responden dengan tingkat pengetauan baik yang memiliki distres diabetes dengan selisih $48,70 \%$. Berdasarkan hasil uji korelasi rank spearman diperoleh nilai $p=0,001$, hal ini berarti ada hubungan yang signifikan antara tingkat pengetahuan dengan distres diabetes pada penderita diabetes mellitus tipe 2 di wilayah kerja Puskesmas Rowosari. Adapun hasil nilai $\mathrm{r}$ adalah -0,654 yang berarti kekuatan korelasi kuat dengan arah hubungan korelasi linear negatif, yang artinya semakin tinggi tingkat pengetahuan maka semakin rendah tingkat distress diabetes pada penderita diabetes mellitus tipe 2 .

Tingkat pengetahuan adalah salah satu hal mendasar yang berpengaruh terhadap cara berpikir dan bertindak seseorang dalam menghadapi sesuatu. Seseorang yang memiliki pengetahuan tentang distress, seperti gejala yang ditimbulkan, bagaimana melakukan menajemen distres dan dampak distress terhadap kesehatannya tentu akan lebih memiliki upaya untuk mengontrol dirinya agar tidak mengalami distres yang berlebihan. Atau apabila itu terjadi, distres yang ada dapat tertangani dengan lebih cepat sehingga tidak akan berdampak buruk bagi kesehatannya. ${ }^{8}$ Karena ketika pasien tidak mampu mengelola stressor dengan baik, maka stressor tersebut yang akhirnya mengakibatkan timbulnya distres pada pasien DM. ${ }^{7}$

Pada penelitian yang dilakukan di RSUD Dr. Moewardi menunjukkan bahwa tingkat pengetahuan dengan distres diabetes memiliki hubungan yang signifikan $(p<0,001)$, Hasil penelitian tersebut menunjukkan proporsi responden dengan tingkat pengetahuan kurang yang memiliki distres diabetes berat 3 kali lebih besar $(3,4 \%)$ dibandingkan proporsi responden dengan tingkat pengetahuan baik yang memiliki distres diabetes berat. ${ }^{5}$ Selain itu, pada penelitian yang dilakukan di San Francisco juga menunjukkan adanya hubungan yang signifikan antara variabel keduanya dengan nilai $p<0,05 .{ }^{1}$ Hal ini mendukung teori bahwa seseorang yang memiliki tingkat pengetahuan terkait distress yang kurang, maka akan lebih berisiko untuk mengalami distress. Hal ini karena penderita tersebut tidak mengetahui terkait besarnya dampak yang dapat ditimbulkan 
dengan munculnya distress terhadap kesehatan penderita maupun keberhasilan pengobatan penderita.

Berdasarkan penjelasan dari hasil penelitian terdahulu, maka diketahui bahwa ada kesesuaian antara teori serta kesesuaian terhadap penelitian sebelumnya dengan hasil analisis hubungan antara tingkat pengetahuan dengan distres diabetes, dimana dari hasil analisis hubungan menunjukan adanya hubungan yang signifikan antara tingkat pengetahuan dengan distres diabetes, dengan tingkat kekuatan hubungan yang tergolong kuat dan bersifat tidak searah ( $p=0,001 ; \alpha=0,05 ; r=-0,654)$. Hal ini berarti, semakin tinggi tingkat pengetahuan maka semakin rendah tingkat distress diabetes pada penderita diabetes mellitus tipe 2 . Hal ini diperkuat dari hasil penelitian bahwa dari 52 penderita distress diabetes, $100 \%$ diantaranya tidak mengetahui/ mengerti istilah distress.

Selain itu, setelah istilah distress dikonversi menjadi stres, masih ada sekitar $46,2 \%$ yang belum mengetahui/ tidak mengerti dengan istilah stress. Dan 92,3\% penderita Distres tidak mengetahui dampak distress terhadap peningkatan gula darah.

\section{DAFTAR PUSTAKA}

1. Fisher L, Mullan JT, Skaff MM, Glasgowt RE, Arean P, Hessler D. Predicting diabetes distress in patients with Type 2 diabetes: A longitudinal study. Diabet Med. 2009;26:6227.

2. Snouffer E, Fisher L. Diabetes Distress: A real and normal part of diabetes. Int Diabetes Fed [Internet]. 2016;62:2. Available from: http://www.idf.org/

3. Gebel E. Diabetes Distress [Internet]. American Diabetes Association. 2013 [cited 2018 Mar 27]. Available from: http://www.diabetes.org/living-withdiabetes/complications/mentalhealth/diabetes-distress.html

4. Islam MR, Islam MS, Karim MR, Alam UK, Yesmin K. Predictors of diabetes distress in patients with type 2 diabetes mellitus. Int $\mathbf{J}$ Res Med Sci [Internet]. 2014;2:631. Available from: http://www.msjonline.org/

5. Berdy R. Hubungan Antara Tingkat Pengetahuan Dengan Tingkat Distres pada Pasien Diabetes Melitus di RSUD Dr.
Perlu diketahui bahwa ketika seseorang mengetahui tentang bahaya risiko yang akan terjadi, maka orang tersebut akan cenderung memiliki keinginan untuk mengelola/ mengatasi distresnya dengan baik agar tidak membahayakan kesehatannya.

\section{SIMPULAN}

Rata-rata lama menderita DM responden sebesar 4,66 tahun, rata-rata skor tingkat pengetahuan sebesar 4,33 poin, dan rata-rata skor distress diabetes sebesar 51,16 poin. Ada hubungan yang signifikan antara lama menderita DM $(\mathrm{p}=$ $0,005 ; \mathrm{r}=-0,280)$ dan tingkat pengetahuan $(\mathrm{p}=$ $0,001 ; r=-0,654)$ dengan distress diabetes pada penderita diabetes mellitus tipe 2 di wilayah kerja Puskesmas Rowosari. Perlu adanya penanganan/ pendekatan terkait distress diabetes pada penderita DM yang baru terdiagnosis menderita DM. Selain itu, perlu adanya peningkatan pemahaman mengenai distress oleh penderita DM. Karena dalam penelitian ini, banyak responden yang belum mengerti apa itu distress, bagaimana dampak yang ditimbulkan, dan cara mengelolanya.

Moewardi Surakarta [Internet]. Universitas Muhammadiyah Surakarta; 2017. Available from:

http://eprints.ums.ac.id/56474/24/Naskah Publikasi.pdf

6. Irfan M, Wibowo H. Hubungan Tingkat Stres Dengan Kadar Gula Darah pada Penderita Diabetes Mellitus (DM) di Puskesmas Peterongan Kabupaten Jombang. J Ilmu Keperawatan [Internet]. 2015;1:8. Available from:

http://garuda.ristekdikti.go.id/journal/article/7 82471

7. Permana YI. Hubungan Antara Lama Sakit Dengan Tingkat Distress pada Pasien Diabetes Mellitus di Rumah Sakit Islam Surakarta [Internet]. Universitas Muhammadiyah Surakarta; 2017 [cited 2018 Apr 2]. Available from: http://eprints.ums.ac.id/52058/2/NASKAH PUBLIKASI.pdf

8. Wade C, Tavris C. Psikologi. 9th ed. Jakarta: Erlangga; 2007. 329 p. 